\title{
Fluorescent detection of singlet oxygen: Amplifying signal transduction and improving sensitivity based on intramolecular FRET of anthryl appended porphyrins
}

\author{
YOU MingXu ${ }^{1}$, WANG YongXiang ${ }^{1}$, WANG Hao ${ }^{1} \&$ YANG RongHua ${ }^{1,2 *}$ \\ ${ }^{1}$ Beijing National Laboratory for Molecular Sciences, College of Chemistry and Molecular Engineering, Peking University, Beijing 100871, \\ China; \\ ${ }^{2}$ State Key Laboratory of Chemo/Biosensing and Chemometrics, Biomedical Engineering Center, College of Chemistry and Chemical Engineering, \\ Hunan University, Changsha 410082, China
}

Received May 30, 2011; accepted August 9, 2011

\begin{abstract}
Two new anthryl-appended porphyrin dyads have been synthesized and used as highly selective and sensitive fluorescence probes for singlet oxygen $\left({ }^{1} \mathrm{O}_{2}\right)$. The design strategy for the probes is directed by the idea of intramolecular fluorescence resonance energy transfer (FRET) interactions and carried out by incorporation of an electron-rich fluorophore (porphyrin) with a reactive anthracene for ${ }^{1} \mathrm{O}_{2}$. The molecular recognition is based on the specific interaction of ${ }^{1} \mathrm{O}_{2}$ with the inner anthracene moiety, and the signal reporter for the recognition process is the porphyrin fluorescence. As a result of overlap of the emission band of the anthracene with the absorbance band of the porphyrin, intramolecular FRET occurs between the anthracene (donor) and the porphyrin (acceptor). The effective light absorbed by the porphyrin and, concomitantly, the emitted light intensity are thus modulated by the emission intensity of the anthracene. Upon reaction with reactive oxygen species such as hydrogen peroxide, hypochlorite, superoxide, hydroxyl radicals, and ${ }^{1} \mathrm{O}_{2}$, the probes exhibit a selective response toward ${ }^{1} \mathrm{O}_{2}$. In addition, significant amplification of the signal transducer is observed. The feasibility of the design was demonstrated by monitoring the ${ }^{1} \mathrm{O}_{2}$ generated from a $\mathrm{MoO}_{4}^{2-} / \mathrm{H}_{2} \mathrm{O}_{2}$ system. The results clearly demonstrate that the synthesized probes exhibit both high selectivity and high sensitivity for ${ }^{1} \mathrm{O}_{2}$. The fluorescence reaction and signal amplification mechanism of the system were both discussed, clearly confirming that the introduction of electron-rich porphyrin units into the 9,10-positions of anthracene can improve the response sensitivity and activate the probe's reactivity toward ${ }^{1} \mathrm{O}_{2}$.
\end{abstract}

${ }^{1} \mathrm{O}_{2}$, anthracene, porphyrin, fluorescence probe, FRET

Citation: You M X, Wang Y X, Wang H, et al. Fluorescent detection of singlet oxygen: Amplifying signal transduction and improving sensitivity based on intramolecular FRET of anthryl appended porphyrins. Chinese Sci Bull, 2011, 56: 3253-3259, doi: 10.1007/s11434-011-4736-0

Singlet oxygen $\left({ }^{1} \mathrm{O}_{2}\right)$, the molecular oxygen with the lowest excited electronic state [1], aroused great interest in the early years because of its oxidative properties in biological and environmental systems. In biological systems, excessive ${ }^{1} \mathrm{O}_{2}$ is thought to be an important toxic species as it can oxidize various kinds of biological molecules such as DNA/ RNA, proteins, and lipids [2]. Moreover, ${ }^{1} \mathrm{O}_{2}$ is one of the most important cytotoxic agents generated during photodynamic therapy by nontoxic photosensitizers with an appro-

*Corresponding author (email: yangrh@pku.edu.cn) priate harmless light source; this is gaining wide acceptance as an alternative noninvasive treatment protocol for destroying malignant cancer cells or tissues in photodynamic therapy [3,4]. In environmental systems, the formation of ${ }^{1} \mathrm{O}_{2}$ in natural water assists in the photodegradation of organic pollutants [5]. The outstanding importance and significant roles of ${ }^{1} \mathrm{O}_{2}$ in research and real-world applications have aroused a demand for detecting it selectively and sensitively.

Monitoring ${ }^{1} \mathrm{O}_{2}$ emissions at $1270 \mathrm{~nm}$ [5] is a direct and noninvasive method to detect ${ }^{1} \mathrm{O}_{2}$; however, this method 
suffers from a weak signal and short ${ }^{1} \mathrm{O}_{2}$ lifetime [6] in aqueous solution as a result of the low emission efficiency of ${ }^{1} \mathrm{O}_{2}$. Chemical trapping combined with optical probes has recently been developed for much more specific, sensitive, and accurate detection of analytes. Anthracene derivatives such as 9,10-diphenylanthracene and 9,10-dimethylanthracene $[7,8]$ are commonly used as ${ }^{1} \mathrm{O}_{2}$ traps; they react specifically with ${ }^{1} \mathrm{O}_{2}$ to form thermostable endoperoxides. Their effectiveness is highly dependent on their ability to transduce the recognition event to a measurable signal because neither the absorbance nor the fluorescence change from anthracene itself as a signal of ${ }^{1} \mathrm{O}_{2}$ production is very sensitive.

Interest in improving the sensitivity for ${ }^{1} \mathrm{O}_{2}$ has led to the development and application of different types of molecular probes, including those based on chemiluminescence, steadystate fluorescence, and time-gated luminescence. One set of widely studied chemiluminescence probes for ${ }^{1} \mathrm{O}_{2}$ are the Cypridina luciferin analogs [9]. Chemiluminescent probes with improved selectivity, based on a thiafulvalene-substituted anthracene trap, have recently been reported $[10,11]$. Many sensitive fluorescent probes for ${ }^{1} \mathrm{O}_{2}$ have recently been developed by conjugating a fluorescein moiety with anthracene derivatives [12], which are characterized by only weak fluorescence in their native state but become highly fluorescent upon reaction with ${ }^{1} \mathrm{O}_{2}$. More recently, rare-metal complexes, such as europium(III) and rhenium(I) chelatebased complexes were used as long-lifetime-based luminescence probes for ${ }^{1} \mathrm{O}_{2}[13,14]$.

Fluorescence resonance energy transfer (FRET) can be applied in fluorescent sensing; this type of sensor is charac- terized by enhanced Stokes' shifts and amplified signal transduction [15]. FRET reactions occurring in porphyrinbased system have attracted considerable attention from researchers [16] because of their tunable fluorescence emissions and outstanding importance in chemical or biological systems containing porphyrin derivatives. It has been observed that intramolecular FRET interactions between anthracenes and porphyrins occur efficiently [17]; in these interactions, anthracene acts as the energy donor and porphyrin as the acceptor. This discovery provides the basis for designing an anthracene-based FRET sensor. However, no attempts, so far, have been made.

In the present study, we propose a new fluorescent sensing approach for ${ }^{1} \mathrm{O}_{2}$ based on the intramolecular FRET interaction between anthracene and porphyrin. To implement our design strategy, two anthryl-appended porphyrin dyads, 1 and 2 (Figure 1), were synthesized. The intramolecular FRET interactions of the dyads were studied. As one example of their analytical application, probe $\mathbf{2}$ was used in fluorescence detection of ${ }^{1} \mathrm{O}_{2}$. This kind of fluorescent probe is characterized by high sensitivity and large Stokes' shifts $(\Delta \lambda>170 \mathrm{~nm})$, which facilitate the separation of the analytical signal from the excitation radiation.

\section{Experimental}

\subsection{Reagents and apparatus}

Anthracene,9-(chloromethyl)anthracene,9,10-(dichloromethyl) anthracene, pyrrole, benzaldehyde, 4-hydroxybenzaldehyde,
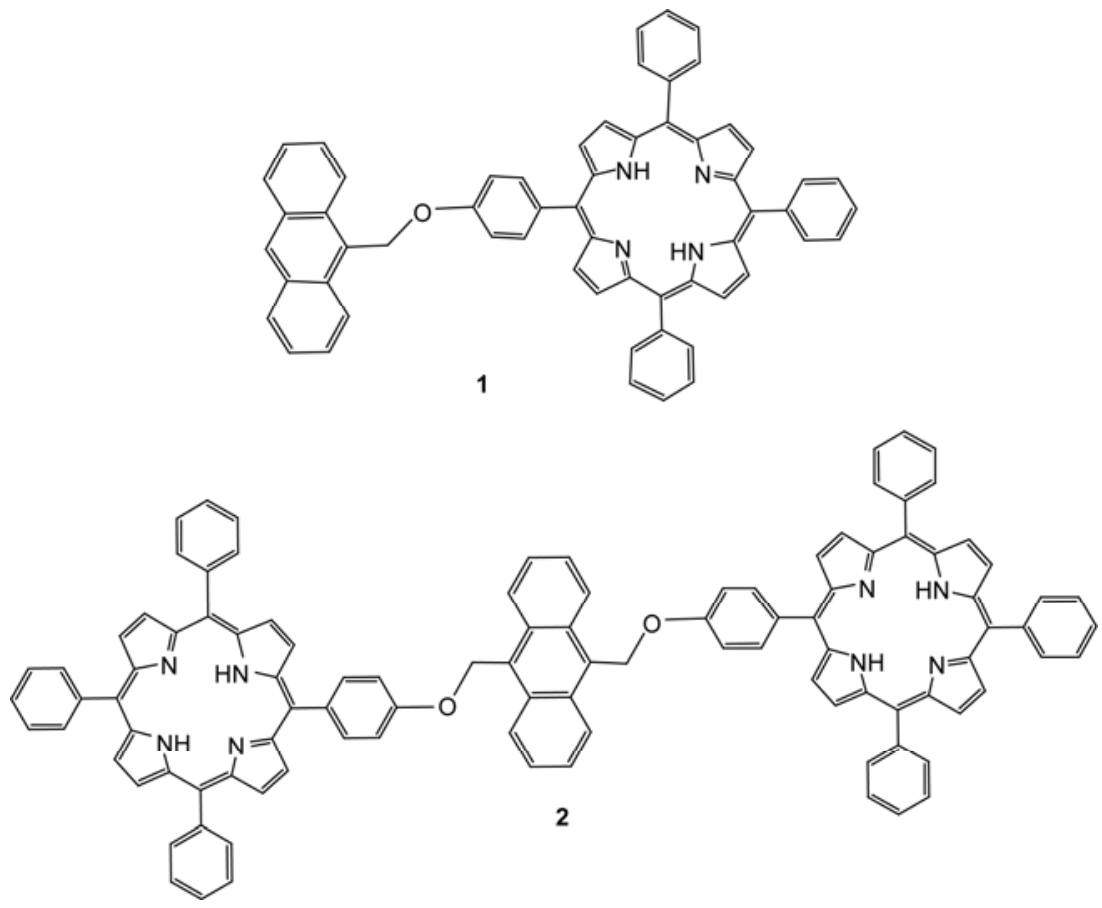

Figure 1 Molecular structures of probes $\mathbf{1}$ and $\mathbf{2}$. 
and meso-tetraphenylporphyrin(TPP) were purchased from Fluka (Switzerland). Sodium molybdate dehydrate $\left(\mathrm{Na}_{2}-\right.$ $\left.\mathrm{MoO}_{4} \cdot 2 \mathrm{H}_{2} \mathrm{O}\right)$, potassium superoxide $\left(\mathrm{KO}_{2}\right)$, and hydrogen peroxide $(30 \%)$ were purchased from the Beijing Chemical Co. (Beijing, China). Pyrrole was used after appropriate distillation and purification. Syntheses and characterizations of probes $\mathbf{1}$ and $\mathbf{2}$ are presented in the Supporting Information $[18,19]$. Stock solutions of anthracene, TPP, $\mathbf{1}$, and $\mathbf{2}$ were obtained by dissolving the materials in analytical grade dimethylformamide (DMF). Prior to use, hydrogen peroxide was diluted immediately from a stabilized $30 \%$ solution, and was assayed using $43.6(\mathrm{~mol} / \mathrm{L})^{-1} \mathrm{~cm}^{-1}$ as the molar absorptivity at $240 \mathrm{~nm}$ [20]. UV-visible absorption spectra were recorded on a Hitachi U-3010 UV/Vis spectrophotometer (Hitachi, Kyoto, Japan). Fluorescence spectra were recorded on a Hitachi F-4500 fluorescence spectrofluorometer (Hitachi); the excitation and emission slit widths were both set at $10.0 \mathrm{~nm}$. The $\mathrm{pH}$ values of the test solutions were measured with a glass electrode connected to a PHS$3 \mathrm{C} \mathrm{pH}$ meter (Shanghai, China) and adjusted if necessary.

\subsection{Fluorescence quenching of anthracene by TPP}

Because of the low solubilities of anthracene and TPP in water, the fluorescence titrations were carried out in a $50 \%$ DMF (v/v) aqueous solution by adding a few microliters of a TPP stock solution to $2.0 \mathrm{~mL}$ of $1.0 \times 10^{-6} \mathrm{~mol} / \mathrm{L}$ anthracene in a quartz cell $(1.0 \mathrm{~cm} \times 1.0 \mathrm{~cm}$ cross-section $)$. The concentration of TPP in the mixture was $5.0 \times 10^{-7}$ to $5.0 \times$ $10^{-6} \mathrm{~mol} / \mathrm{L}$; the addition was limited to $100 \mu \mathrm{L}$ so that the volume change was insignificant. The fluorescence emission spectra were obtained by exciting at the maximum absorption wavelength of anthracene. The obtained data on the intensity ratio of the system at 652 and $416 \mathrm{~nm}$ were analyzed to test the energy-transfer efficiency.

\section{$1.3{ }^{1} \mathrm{O}_{2}$ reaction and detection}

All experiments were run at $25^{\circ} \mathrm{C}$ in $50 \times 10^{-3} \mathrm{~mol} / \mathrm{L}$ sodium phosphate buffer saline (PBS) containing 50\% (v/v) DMF as a cosolvent, unless otherwise stated. The method for chemically generating ${ }^{1} \mathrm{O}_{2}$ was adapted from the $\mathrm{MoO}_{4}^{2-}$ / $\mathrm{H}_{2} \mathrm{O}_{2}$ system, as previously reported by Aubry et al. [21]. Typically, an appropriate amount of $\mathrm{Na}_{2} \mathrm{MoO}_{4}(0.01 \mathrm{~mol} / \mathrm{L})$ was first added to $\sim 1 \mathrm{~mL}$ of the $\mathrm{DMF}$ aqueous solution containing the probe, and the mixture was diluted to $2 \mathrm{~mL}$ with PBS. The reaction was initiated by introducing a small amount freshly diluted hydrogen peroxide solution (typically $20 \mu \mathrm{L}$ ) into the mixture solution. After standing for $5 \mathrm{~min}$ at room temperature, the fluorescence emission of $\mathbf{2}$ was measured with an excitation wavelength of $368 \mathrm{~nm}$. For the selectivity experiments, the reactions of $\mathbf{2}$ with other reactive oxygen species (ROS) were studied. Hydroxyl radicals $(\cdot \mathrm{OH})$ were generated in a Fenton's reagent system of ferrous ammonium sulfate and hydrogen peroxide [22]. A superoxide $\left(\mathrm{O}_{2}^{-\cdot}\right)$ solution was prepared by adding $\mathrm{KO}_{2}$ to dry dimethyl sulfoxide and stirring vigorously for $5 \mathrm{~min}$ [23]. These reactive species were used immediately after generation.

\section{Results and discussion}

\subsection{Energy-transfer interactions between anthracene and porphyrin}

Fluorescence energy transfer is the transfer of the excitation energy from an initially excited donor (D) to an acceptor (A). The efficiency of energy transfer depends mainly on the extent of spectral overlap of the emission spectrum of the donor with the absorption spectrum of the acceptor, and the distance between the donor and acceptor molecules. Figure 2 shows the fluorescence emission spectrum of anthracene and the electronic absorption spectrum of TPP in DMF aqueous solution. Excitation of anthracene at $368 \mathrm{~nm}$ emits strong fluorescence, and the corresponding emission peak maxima are located at 397 and $416 \mathrm{~nm}$, respectively. It can be seen that there is significant spectral overlap of the $416 \mathrm{~nm}$ emission band of anthracene with the $419 \mathrm{~nm}$ Soret band of TPP. This spectral overlapping meets the precondition for electronic energy-transfer interactions between anthracene and TPP. To check whether energy transport from an electronically excited anthracene to TPP is possible, the effect of TPP on the fluorescence emission of anthracene was studied (Figure 2, inset). The addition of increasing concentrations of TPP to a solution of anthracene and

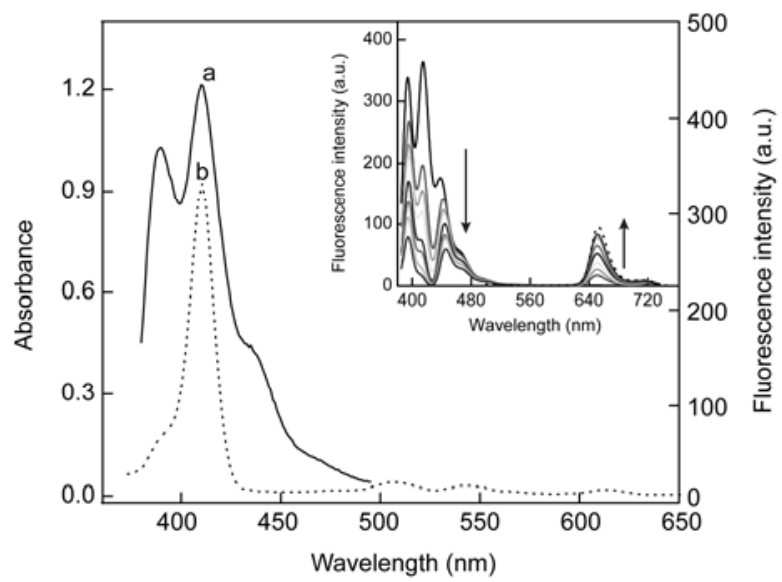

Figure 2 Fluorescence emission spectrum of anthracene (a, $\lambda_{\mathrm{ex}}=368 \mathrm{~nm}$ ) and the UV-visible absorption spectrum of TPP (b) in DMF aqueous solution. The concentrations of TPP and anthracene are $5.0 \times 10^{-6} \mathrm{~mol} / \mathrm{L}$. Inset: fluorescence emission spectral changes $\left(\lambda_{\mathrm{ex}}=368 \mathrm{~nm}\right)$ of a mixture of anthracene $\left(1.0 \times 10^{-6} \mathrm{~mol} / \mathrm{L}\right)$ and TPP with different TPP amounts. The arrows show the dependence of the emission spectra of anthracene and TPP on the TPP concentration. The dashed line is the emission spectrum of TPP $\left(1.0 \times 10^{-5} \mathrm{~mol} / \mathrm{L}\right)$, with an excitation wavelength of $420 \mathrm{~nm}$. 
excitation at $368 \mathrm{~nm}$ results in an apparent decrease in the $416 \mathrm{~nm}$ emission band of anthracene and a concomitant progressive increase in TPP fluorescence emission, with the maximum centered around $652 \mathrm{~nm}$. At TPP concentrations greater than 2.5 equiv. relative to the anthracene concentration, no obvious changes in either the anthracene or TPP fluorescences are observed. These fluorescence emission changes in both fluorophores suggest that fluorescence energy transfer occurred from the donor, anthracene, to the acceptor, TPP; this constitutes the basis for designing a FRET-based fluorescent probe.

\subsection{Probe designs and optical properties}

Anthracene derivatives react rapidly with ${ }^{1} \mathrm{O}_{2}$ specifically to form a thermostable endoperoxide. This endoperoxide formation causes strong fluorescence quenching of anthracene. However, UV light excitation and emission, and the short Stokes' shift $(\Delta \lambda<45 \mathrm{~nm})$ of anthracenes limit their application as an efficient fluorescent probe for ${ }^{1} \mathrm{O}_{2}$. On the other hand, as mentioned above, the fluorescence emission of anthracene could be reported by porphyrin via a FRET process. We thus introduce an acceptor molecule, porphyrin, into the anthracene moiety to signal the molecular recognition event for ${ }^{1} \mathrm{O}_{2}$, and an amplified signal transduction might be expected to occur during the oxidation of anthracene. At the beginning of this investigation, two functionalized anthracene molecules, $\mathbf{1}$ and $\mathbf{2}$, were synthesized by introducing different stoichiometric porphyrin moieties into the molecular backbone of anthracene (Figure 1). Besides the original reactive anthryl group as the energy donor, $\mathbf{1}$ and $\mathbf{2}$ contain one or two porphyrin moiety/moieties which worked as the energy acceptor. A spacer, $-\mathrm{OCH}_{2}-$, was introduced to separate the donor and acceptor units; this does not influence the basic electronic structure of the donor and acceptor.

Figure 3 shows UV-visible absorption spectra of $\mathbf{1}$; it is a superposition of the spectra of the porphyrin and anthracene units, and shows no significant perturbations. The maximum absorption wavelength of TPP occurs at $416 \mathrm{~nm}$, and the maxima in the Q-band region are at 504 and $546 \mathrm{~nm}$, respectively. These absorption bands are essentially identical to those observed from TPP. An intense absorption band occurs at 260-290 nm, which is the region of the second singlet of anthracene, indicating that no ground-state interaction occurs between the two fluorophores. On the contrary, the fluorescence features of the probes greatly differ from those of the simple anthracene and TPP molecules. The inset in Figure 3 shows the fluorescence emission spectra of $\mathbf{1}$ and $\mathbf{2}$ in DMF aqueous solution; both spectra display obvious TPP emission by the excitation of the donor moiety of anthracene at $368 \mathrm{~nm}$. Moreover, compared with the emission spectrum of the anthracene+TPP mixture, the two spectra show intensity decreases in donor emissions but intensity increases in acceptor emissions. For instance, the

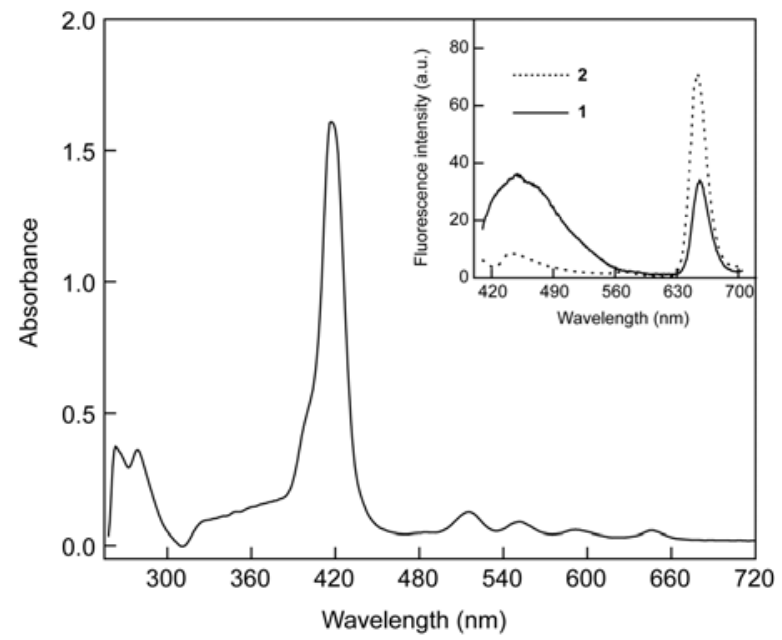

Figure 3 UV-visible absorption spectrum of $1\left(1.0 \times 10^{-5} \mathrm{~mol} / \mathrm{L}\right)$ in DMF aqueous solution at $\mathrm{pH}$ 7.1. Inset: fluorescence emission spectra of $\mathbf{1}$ and $\mathbf{2}$ $\left(2.0 \times 10^{-6} \mathrm{~mol} / \mathrm{L}\right)$ in DMF aqueous solution; both spectra were recorded with an excitation wavelength of $368 \mathrm{~nm}$.

intensity ratio, $I_{652} / I_{416}$, of 2 is 7.10 , which is 3-fold higher than the $I_{652} / I_{416}$ value of 2.4 for the anthracene+TPP ( $n_{\text {anthracene }}$ : $\left.n_{\mathrm{TPP}}=1: 2\right)$. Collectively, the results provide evidence of intramolecular FRET from the anthracene to the porphyrin, and the FRET is more efficient here in an intramolecular situation than it is in intermolecular situations, suggesting that the short ether spacer moiety $\left(-\mathrm{OCH}_{2}-\right)$ of the donor and acceptor makes the main contribution to the energytransfer efficiency.

\subsection{Fluorescence responses of the probes to ROS}

Fluorescence responses of $\mathbf{1}$ and $\mathbf{2}$ to ${ }^{1} \mathrm{O}_{2}$ were first examined and compared with those of anthracene and TPP in DMF aqueous solution at $\mathrm{pH} 10.2$ using $\mathrm{MoO}_{4}^{2-} / \mathrm{H}_{2} \mathrm{O}_{2}$ as the ${ }^{1} \mathrm{O}_{2}$ source (Figure 4). In the absence of ${ }^{1} \mathrm{O}_{2}$, all the dyes showed strong fluorescence emissions, and the fluorescence of anthracene could be reported by the TPP emission in the cases of $\mathbf{1}$ and $\mathbf{2}$. The dotted lines in Figure 4 show the fluorescence emission spectra of the probes in the presence of $1.0 \times 10^{-3} \mathrm{~mol} / \mathrm{L}^{1} \mathrm{O}_{2}$. Fluorescence quenching was observed in all cases, but the fluorescence-quenching efficiencies were different. The strong quenching of anthracene by ${ }^{1} \mathrm{O}_{2}$ results from the formation of endoperoxide, and the slight quenching of TPP (Figure 4(b)) by ${ }^{1} \mathrm{O}_{2}$ is probably caused by a weak interaction between the neutral ${ }^{1} \mathrm{O}_{2}$ and the porphyrin ring. Interestingly, we noted that for the probes $\mathbf{1}$ and $\mathbf{2}$, higher quenching efficiency was observed compared with those of anthracene or TPP alone under the same conditions. This strong TPP fluorescence quenching of $\mathbf{1}$ or $\mathbf{2}$ by ${ }^{1} \mathrm{O}_{2}$ provides a basis for using them as fluorescence probes for detection of ${ }^{1} \mathrm{O}_{2}$ as they enhance the Stoke's shift and amplify signal transduction.

To study the reaction specificity of the probes with ${ }^{1} \mathrm{O}_{2}, 2$ 

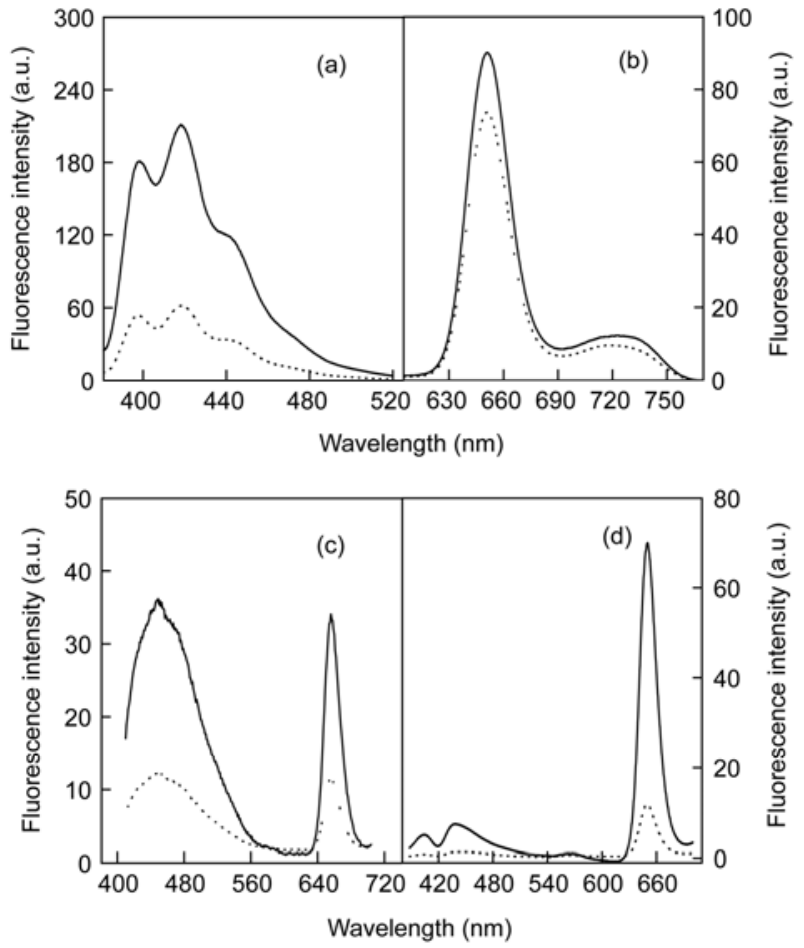

Figure 4 Fluorescence emission spectra of anthracene (a, $\lambda_{\mathrm{ex}}=368 \mathrm{~nm}$ ), TPP (b, $\left.\lambda_{\mathrm{ex}}=420 \mathrm{~nm}\right), \mathbf{1}\left(\mathrm{c}, \lambda_{\mathrm{ex}}=368 \mathrm{~nm}\right)$, and $\mathbf{2}\left(\mathrm{d}, \lambda_{\mathrm{ex}}=368 \mathrm{~nm}\right)$ before $(-)$ and after $(\cdots)$ reaction with ${ }^{1} \mathrm{O}_{2}\left(2.0 \times 10^{-3} \mathrm{~mol} / \mathrm{L}\right)$ in $\mathrm{DMF}$ aqueous solution at $\mathrm{pH}$ 10.2. The concentrations of all the dyes were $2.0 \times 10^{-6} \mathrm{~mol} / \mathrm{L}$.

was subjected to biological or environmental ROS. The ROS $\left(\mathrm{ClO}^{-}, \cdot \mathrm{OH}, \mathrm{H}_{2} \mathrm{O}_{2}\right.$, or $\left.\mathrm{O}_{2}^{-\cdot}\right)$ was used immediately after preparation, as mentioned in the experimental section. The fluorescence response of the probe to ${ }^{1} \mathrm{O}_{2}$ gives good selectivity over other ROS, as shown in Figure 5. The TPP fluorescence intensity of the products of 2 reacted with either $\mathrm{ClO}^{-}, \cdot \mathrm{OH}, \mathrm{H}_{2} \mathrm{O}_{2}, \mathrm{O}_{2}^{-\cdot}$ or did not change noticeably, whereas a significant TPP fluorescence decrease was observed

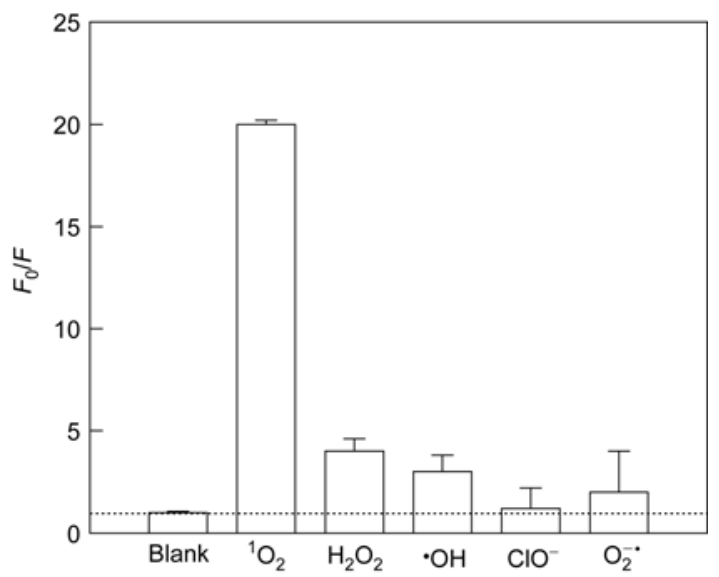

Figure 5 Fluorescence intensity decreases of the products of $2\left(2.0 \times 10^{-6}\right.$ $\mathrm{mol} / \mathrm{L})$ reacted with different $\operatorname{ROS}\left(2.0 \times 10^{-3} \mathrm{~mol} / \mathrm{L}\right)$ in $\mathrm{DMF}$ aqueous solution at $\mathrm{pH} 10.2$. The fluorescence intensity was recorded at $652 \mathrm{~nm}$ with an excitation wavelength of $368 \mathrm{~nm}$. after the complex was reacted with $\mathrm{MoO}_{4}^{2-}$ in the presence of $\mathrm{H}_{2} \mathrm{O}_{2}$. To test whether the TPP fluorescence change of $\mathbf{2}$ is induced by ${ }^{1} \mathrm{O}_{2}$, a ${ }^{1} \mathrm{O}_{2}$ quencher, sodium azide, was used. When enough sodium azide was added to the mixture solution of $\mathrm{H}_{2} \mathrm{O}_{2} / \mathrm{MoO}_{4}^{2-} / 2$, a fluorescence change of TPP was not observed. These results indicate that the probe exhibits a highly selective fluorescence response to ${ }^{1} \mathrm{O}_{2}$ instead of to another ROS; this may be attributed to the specific reactivity of the anthracene unit toward ${ }^{1} \mathrm{O}_{2}$, as expected.

\subsection{Detection of ${ }^{1} \mathrm{O}_{2}$}

Because of the higher fluorescence-quenching efficiency of $\mathbf{2}$ than that of $\mathbf{1}$, for the present study, we focused primarily on 2 to characterize the sensitivity and selectivity for ${ }^{1} \mathrm{O}_{2}$ detection. Because ${ }^{1} \mathrm{O}_{2}$ can be quantitatively generated in a weakly basic aqueous buffer through $\mathrm{H}_{2} \mathrm{O}_{2}$ disproportionation catalyzed by molybdate ion, $\mathrm{H}_{2} \mathrm{O}_{2} / \mathrm{MoO}_{4}^{2-}$ was used as a chemical source of ${ }^{1} \mathrm{O}_{2}$ to investigate the reaction of $\mathbf{2}$ with ${ }^{1} \mathrm{O}_{2}$. One ${ }^{1} \mathrm{O}_{2}$ molecule can be formed quantitatively by the reaction of two $\mathrm{H}_{2} \mathrm{O}_{2}$ molecules [24]. Figure 6 shows the fluorescence emission spectral changes of $\mathbf{2}$ as a function of the concentration of ${ }^{1} \mathrm{O}_{2}$. The reaction was performed at $\mathrm{pH}$ 10.2 by adding increasing concentrations of $\mathrm{H}_{2} \mathrm{O}_{2}$ to a buffered solution of 2 and $\mathrm{MoO}_{4}^{2-}\left(1.0 \times 10^{-2} \mathrm{~mol} / \mathrm{L}\right)$ every $5 \mathrm{~min}$. The fluorescence spectra were recorded at $\lambda_{\mathrm{ex}}=368 \mathrm{~nm}$ and $\lambda_{\mathrm{em}}=390-700 \mathrm{~nm}$. Decreases in fluorescence at the emission maxima of 450 and $652 \mathrm{~nm}$ were observed as the concentration of $\mathrm{H}_{2} \mathrm{O}_{2}$ increased. When the $\mathrm{H}_{2} \mathrm{O}_{2}$ concentration was about $1.0 \times 10^{-2} \mathrm{~mol} / \mathrm{L}$, the fluorescence intensity gradually leveled off (about $98 \%$ decrease at $652 \mathrm{~nm}$ ). This illustrates that the probe can be used for the quantitative detection

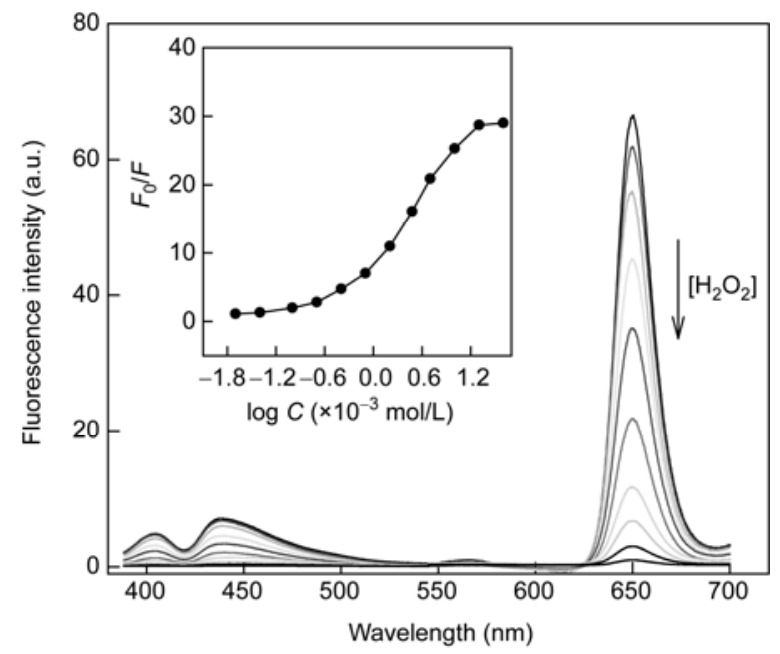

Figure 6 Fluorescence emission spectra of $2\left(2.0 \times 10^{-6} \mathrm{~mol} / \mathrm{L}, \lambda_{\mathrm{ex}}=368\right.$ $\mathrm{nm}$ ) in the presence of varying concentrations of $\mathrm{H}_{2} \mathrm{O}_{2}$. The reaction was performed at room temperature for $5 \mathrm{~min}$ with $6.0 \times 10^{-3} \mathrm{~mol} / \mathrm{L} \mathrm{Na}_{2} \mathrm{MoO}_{4}$ in DMF aqueous solution at $\mathrm{pH} 10.2$. Inset: the dependences of the TPP fluorescence intensity ratios at $652 \mathrm{~nm}, F_{0} / F$, on different concentrations of ${ }^{1} \mathrm{O}_{2}$. 
of ${ }^{1} \mathrm{O}_{2}$. From Figure 6, it can be seen that the response of 2 to ${ }^{1} \mathrm{O}_{2}$ at $652 \mathrm{~nm}$ is more sensitive than that at $450 \mathrm{~nm}$ because of the amplification of the signal transduction through the FRET process. In our subsequent experiments, quantitative measurements were made at $\lambda_{\mathrm{ex}}=368 \mathrm{~nm}$ and $\lambda_{\mathrm{em}}=652 \mathrm{~nm}$. There is a good linear relationship between the fluorescence emission change, $F_{0} / F$, and the ${ }^{1} \mathrm{O}_{2}$ concentration range from $2.0 \times 10^{-6}$ to $4.0 \times 10^{-3} \mathrm{mmol} / \mathrm{L}\left(F_{0} / F=1.12+6.02 C\right.$, $R^{2}=0.997$, Figure 6 , inset), where $F_{0}$ and $F$ are the fluorescence intensity of 2 at $652 \mathrm{~nm}$ in the absence and the presence of ${ }^{1} \mathrm{O}_{2}$. The detection limit, which is taken to be three times the standard derivation in a blank solution, was estimated to be about $2.4 \times 10^{-8} \mathrm{~mol} / \mathrm{L}$.

\subsection{Mechanism for sensitivity improvement}

To investigate mechanisms for sensitivity improvement of the present system, the reactions of $\mathbf{1}, \mathbf{2}$, and their reference compounds (anthracene, TPP, and a mixture of anthracene+ TPP) with ${ }^{1} \mathrm{O}_{2}$ were compared. Figure 7 shows linear SternVolmer plots of the compounds against increased concentrations of ${ }^{1} \mathrm{O}_{2}$. Although the interaction of each compound with ${ }^{1} \mathrm{O}_{2}$ caused fluorescence quenching, a much stronger fluorescence quenching constant was observed with $\mathbf{1}$ and $\mathbf{2}$, particularly 2 , than with the reference compounds. The SternVolmer constant of 2, $K_{\text {sv }}$, is $6020 \mathrm{~L} / \mathrm{mol}$, about 23-fold higher than that of anthracene, and 7-fold higher than that of the anthracene+TPP system. The observed results suggest that the response sensitivity of anthracene toward ${ }^{1} \mathrm{O}_{2}$ could be improved greatly using an intramolecular FRET mechanism.

The improvement in the sensitivity of the energy-transfer system could be estimated quantitatively by the Levitsky model [25]. If $F_{0}$ and $F$ are the fluorescence intensities of a

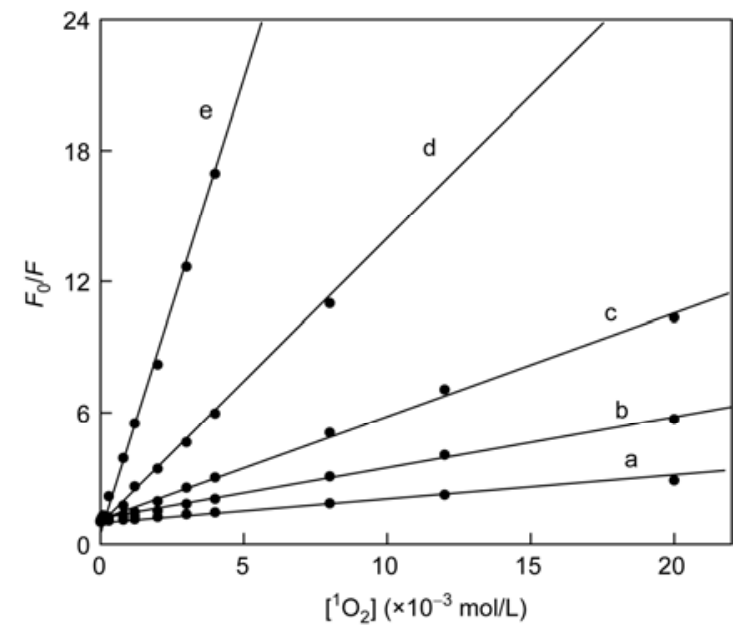

Figure 7 Stern-Volmer plots for fluorescence quenching by ${ }^{1} \mathrm{O}_{2}$ : (a) TPP with excitation at $420 \mathrm{~nm}$ and monitored at $652 \mathrm{~nm}$; (b) anthracene with excitation at $368 \mathrm{~nm}$ and monitored at $416 \mathrm{~nm}$; (c) a mixture of anthracene+TPP ( $n_{\text {anthracene }}: n_{\mathrm{TPP}}=1: 2$ ) with excitation at $368 \mathrm{~nm}$ and monitored at $652 \mathrm{~nm}$; (d) probe 1 with excitation at $368 \mathrm{~nm}$ and monitored at $652 \mathrm{~nm}$; (e) probe 2 with excitation at $368 \mathrm{~nm}$ and monitored at $652 \mathrm{~nm}$. sensing system in the absence and the presence of an analyte, according to the Levitsky model, the sensitivity of a system containing a monofluorophore can be described by

$$
S_{\mathrm{M}}=\frac{F}{F_{0}}=\frac{k^{0} N}{k N^{0}}=K_{\mathrm{B}} \times \frac{k^{0}}{k},
$$

where $k^{0}$ and $k$ are the deactivation rates (inverse lifetimes) of the excited fluorophore prior to and after analyte interaction, respectively; $N$ is the number of fluorophores transferred to the new excited state after analyte interaction; $N^{0}$ is the total number of fluorophores, and $K_{\mathrm{B}}=N / N^{0}$ is the binding constant for the analyte-fluorophore interaction.

For a sensing system containing a bifluorophore in which the donor is selectively excited, and the response fluorescence is obtained from the acceptor, the corresponding sensitivity, $S_{\mathrm{B}}$, is given by [25]

$$
S_{\mathrm{B}}=\frac{F_{\mathrm{A}}}{F_{\mathrm{A}}^{0}}=K_{\mathrm{BD}} \times K_{\mathrm{BA}} \times \frac{k_{\mathrm{D}}^{0}}{k_{\mathrm{D}}} \times \frac{k_{\mathrm{A}}^{0}}{k_{\mathrm{A}}} \times \frac{I_{\mathrm{OV}}}{I_{\mathrm{OV}}^{0}} .
$$

Here, $K_{\mathrm{BD}}$ and $K_{\mathrm{BA}}$ are the binding constants for the donoranalyte interaction and acceptor-analyte interaction, respectively; $k_{\mathrm{D}}^{0}$ and $k_{\mathrm{D}}$ are the deactivation rates of the excited donor prior to and after analyte interaction, respectively; $k_{\mathrm{A}}^{0}$ and $k_{\mathrm{A}}$ are the deactivation rates of the excited acceptor prior to and after analyte interaction, respectively; and $I_{\mathrm{OV}}$ is the overlapping integral between the acceptor absorption and donor fluorescence spectra. The stronger the overlap between the donor and acceptor spectra, the higher the $I_{\mathrm{OV}}$ and energy-transfer rate.

By comparing eqs. (1) and (2), it is clear that the sensitivity is amplified for a bifluorophore system with respect to that of a monofluorophore. Because of the significant overlap between the anthracene emission spectrum and the TPP absorption spectrum, and the flexible $-\mathrm{OCH}_{2}-$ linkage between the intermolecular anthracene and TPP moieties, it is reasonable that the ${ }^{1} \mathrm{O}_{2}$ fluorescence quenching results obtained with $\mathbf{1}$ and $\mathbf{2}$ are higher than those obtained using one monofluorophore, anthracene, or a mixture of anthracene and TPP.

\section{Conclusion}

The work described here demonstrates the feasibility of exploiting the FRET process as a basis for the fluorescent detection of ${ }^{1} \mathrm{O}_{2}$. Compared with classical fluorescent probes based on one monofluorophore, this kind of FRETbased probe is characterized by large Stokes' shifts, which facilitate the separation of the analytical signal from the excitation radiation and by the amplification of the fluorescence signal transducer. The results described here clearly demonstrate that the synthesized probe 2 exhibits both high selectivity and high sensitivity to ${ }^{1} \mathrm{O}_{2}$, which makes it possible to use it widely for ${ }^{1} \mathrm{O}_{2}$ detection in many chemical 
and biological systems and even in the presence of other ROS. Although we used this approach to demonstrate the detection of ${ }^{1} \mathrm{O}_{2}$ based on the TPP fluorescence-quenching effect, the strategy is versatile and can be used with other types of analyte so that signal-on detection can be easily adapted.

This work was supported by the National Natural Science Foundation of China (21075032, 21005026), the National Grand Program on Key Infectious Diseases (2009ZX100 04-312), the Hunan Province Key Project of Scientific and Technical Programs (2010TP4013-1), and Program for Changjiang Scholars and Innovative Research Team in University.

1 Foote C S. Mechanisms of photosensitized oxidation. Science, 1968, 162: 963-970

2 GretherBeck S, OlaizolaHorn S, Schmitt H, et al. Activation of transcription factor AP-2 mediates UVA radiation-and singlet oxygen-induced expression of the human intercellular adhesion molecule 1 gene. Proc Natl Acad Sci USA, 1996, 93: 14586-14591

3 Beverina L, Crippa M, Landenna M, et al. Assessment of water-soluble $\pi$-extended squaraines as one- and two-photon singlet oxygen photosensitizers: Design, synthesis, and characterization. J Am Chem Soc, 2008, 130: 1894-1902

4 Castano A P, Mroz P, Hamblin M R. Photodynamic therapy and antitumour immunity. Nat Rev Cancer, 2006, 6: 535-545

5 Miller J S. Rose bengal-sensitized photooxidation of 2-chlorophenol in water using solar simulated light. Water Res, 2005, 39: 412-422

6 Nonell S, Braslavsky S E. Time-resolved singlet oxygen detection. Method Enzymol, 2000, 319: 37-49

7 Schweitzer C, Schmidt R. Physical mechanisms of generation and deactivation of singlet oxygen. Chem Rev, 2003, 103: 1685-1757

8 Steinbeck M J, Khan A U, Karnovsky M J. Intracellular singlet oxygen generation by phagocytosing neutrophils in response to particles coated with a chemical trap. J Biol Chem, 1992, 19: 13425-13433

9 Goto T, Takagi T. Chemiluminescence of a cypridina luciferin analogue, 2-methyl-6-phenyl-3,7-dihydroimidazo[1,2-a]pyrazin-3-one, in the presence of the xanthine-xanthine oxidase system. Bull Chem Soc Jpn, 1980, 53: 833-834

10 Li X, Zhang G, Ma H, et al. 4,5-Dimethylthio-4'-[2-(9-anthryloxy) ethylthio]tetrathiafulvalene, a highly selective and sensitive chemiluminescence probe for singlet oxygen. J Am Chem Soc, 2004, 126: 11543-11548

11 MacManus-Spencer L A, Latch D E, Kroncke K M, et al. Stable dioxetane precursors as selective trap-and-trigger chemiluminescent probes for singlet oxygen. Anal Chem, 2005, 77: 1200-1205

12 Umezawa N, Tanaka K, Urano Y, et al. Novel fluorescent probes for singlet oxygen. Angew Chem Int Ed, 1999, 38: 2899-2901

13 Song B, Wang G, Tan M, et al. A europium(III) complex as an efficient singlet oxygen luminescence probe. J Am Chem Soc, 2006, 128: $13442-13450$

14 Liu Y J, Wang K Z. Visible-light-excited singlet-oxygen luminescence probe based on $\operatorname{Re}(\mathrm{CO})_{3} \mathrm{Cl}($ aeip). Eur J Inorg Chem, 2008, 2008: 5214-5219

15 Lacowitz J R. Principles of Fluorescence Spectroscopy. New York: Plenum Press, 2006

16 Gust D, Moore T A. Photosynthetic model systems. Top Curr Chem, 1991, 159: 103-151

17 Effenberger F, Schlosser H, Baverle P, et al. Synthesis and optical properties of terminally substituted conjugated polyenes. Angew Chem Int Ed, 1988, 27: 281-284

18 Adler A D, Longo F R, Finarelli J D. A simplified synthesis for mesotetraphenylporphine. J Org Chem, 1967, 32: 476

19 Sirish M, Maiya B G. Fluorescence studies on a supramolecular porphyrin bearing anthracene donor moieties. J Photochem Photobiol AChem, 1995, 85: 127-135

20 Lei B, Adachi N, Arai T. Measurement of the extracellular $\mathrm{H}_{2} \mathrm{O}_{2}$ in the brain by microdialysis. Brain Res Protoc, 1998, 3: 33-36

21 Aubry J M, Cazin B. Chemical sources of singlet oxygen. 2. Quantitative generation of singlet oxygen from hydrogen peroxide disproportionation catalyzed by molybdate ions. Inorg Chem, 1988, 27: 2013-2014

22 Walling C. Fenton's reagent revisited. Acc Chem Res, 1975, 8: 125-131

23 Zhao H T, Kalivendi S, Zhang H, et al. Superoxide reacts with hydroethidine but forms a fluorescent product that is distinctly different from ethidium: Potential implications in intracellular fluorescence detection of superoxide. Free Radic Biol Med, 2003, 34: 1359-1368

24 Aubry J M, Pierlot C, Rigaudy J, et al. Reversible binding of oxygen to aromatic compounds. Acc Chem Res, 2003, 36: 668-675

25 Levitsky I A, Krivoshlykov S G, Grate J W. Signal amplification in multichromophore luminescence-based sensors. J Phys Chem B, 2001, 105: 8468-8473

Open Access This article is distributed under the terms of the Creative Commons Attribution License which permits any use, distribution, and reproduction in any medium, provided the original author(s) and source are credited.

\section{Supporting Information}

Synthesis of $\mathbf{1}$ and $\mathbf{2}$, and the fluorescence response of $\mathbf{1}$ toward different concentrations of ${ }^{1} \mathrm{O}_{2}$.

Scheme S1 Reaction scheme for synthesis of probes of $\mathbf{1}$ and $\mathbf{2}$.

Figure S1 Fluorescence emission spectra of $1\left(2.0 \times 10^{-6} \mathrm{~mol} / \mathrm{L}, \lambda_{\mathrm{ex}}=368 \mathrm{~nm}\right)$ in the presence of varying concentrations of $\mathrm{H}_{2} \mathrm{O}_{2}$. The reaction was performed at room temperature for $5 \mathrm{~min}$ with $6.0 \times 10^{-3} \mathrm{~mol} / \mathrm{L} \mathrm{Na}_{2} \mathrm{MoO}_{4}$ in $\mathrm{DMF}$ aqueous solution at $\mathrm{pH} 10.2$.

The supporting information is available online at csb.scichina.com and www.springerlink.com. The supporting materials are published as submitted, without typesetting or editing. The responsibility for scientific accuracy and content remains entirely with the authors. 